\title{
Determinação dos multiplicadores da matriz de contabilidade social, da indústria de base florestal paranaense - 1998
}

Ricardo Kureski ${ }^{1}$

Blas E. Caballero Nuñez ${ }^{2}$

RESUMO: Este artigo tem como objetivo mensurar o impacto do aumento da demanda final da indústria de base florestal. Como instrumento de análise utiliza-se a matriz de contabilidade social do Estado do Paraná de 1998. Foi necessário calcular o multiplicares da matriz. Os efeitos de uma injeção nas variáveis exógenas sobre os segmentos de Madeira e Mobiliário e de Papel e Papelão resultaram em choques de demanda mais intensos dentro do próprio setor. Observa-se que o ramo de Madeira e Mobiliário tem maiores ligações com as atividades relativas ao setor terciário; já o segmento de Papel e Papelão, com atividades que necessitam embalagem. Conclui-se que, apesar da agregação das atividades econômicas da matriz de contabilidade social paranaense, foi possível identificar os principais impactos decorrentes do aumento da demanda final.

Palavras-chave: Matriz de contabilidade social; Multiplicadores; Paraná; Indústria.

Classificação JEL: R10, R15, R19.

1 Doutor em Economia e Política Florestal (UFPR). Professor da Pontifícia Universidade Católica do Paraná. Pesquisador do Ipardes. E-mail: kureski@pr.gov.br.

2 Doutor em Economia (USP). Professor do Programa de Pós-Graduação em Economia e Política Florestal da UFPR. E-mail: blas@ufpr.br. 
Abstract: The present article aims at measuring the final demand impact on the forest-based industry by using the 1998 State of Parana social accounting matrix as the analysis tool. We also had to calculate the matrix multipliers. The increased effects of exogenous activity on the Wood/Furniture and Paper/Pulp activities brought a more intense demand shock to that sector. We noticed that the Wood and Furniture activity is mostly connected with the tertiary sector activities, while the Paper and Pulp activity is mostly connected with activities that need packing. Finally, we could identify the main impacts originated by an increased final demand in spite of the reduction in the number of Parana Social Accounting Matrix economic activities.

Key-words: Social Accounting Matrix, Multipliers, Paraná and Industry.

JEL Classification: R10, R15, R19.

\section{Introdução}

A indústria de papel surgiu no Brasil no final do século XIX. O resultado do recenseamento industrial de 1907 demonstrou que havia 17 estabelecimentos produtores de papel e papelão no Brasil, sendo um no Paraná. As máquinas e as matérias-primas eram importadas dos Estados Unidos e da Europa. A partir da década de 1930, ocorreu um incremento na produção de papel, entretanto os papéis finos e os de imprensa continuavam a ser importados. A partir dos anos 40, a Carteira de Crédito Agrícola e Industrial do Banco do Brasil concedeu empréstimos de longo prazo para a criação de novas indústrias de papel e celulose, porém, com o advento da Segunda Guerra Mundial, ocorreu retração nesse segmento industrial, em função da dificuldade de importar matérias-primas e máquinas. Com a liberação das importações, ao término da guerra, retomaram-se as importações de papel, mas com menor participação no consumo aparente, devido ao crescimento da produção interna (PALADINO, 1985).

Em 1966, mediante incentivos fiscais, o governo desenvolveu a atividade de reflorestamento. Em 1974 tem-se o primeiro Programa Nacional de Papel e Celulose (PNPC), cujas metas de produção para 1980 
visavam à auto-suficiência e à exportação do excedente. Contudo, não se atingiram as metas na produção de papel jornal e celulose.

Mattos e Valença (1999) mencionam que as vantagens climáticas, a extensão territorial e a tecnologia florestal evoluída permitiram ao país passar de uma insignificante participação no cenário mundial de papel e celulose no início da década de 1970 para uma posição de relativo destaque ao final da década de 1980. Em 1998, o setor faturou US\$ 6,7 bilhões, ficando na sétima posição entre os produtores mundiais de celulose e na $12 .{ }^{a}$ posição com relação à produção de papel.

Quanto à indústria de móveis, Santos (1999) a descreve como geograficamente dispersa por todo território nacional, localizando-se principalmente na Região Centro-Sul do país, que responde por $90 \%$ da produção nacional e $70 \%$ da mão-de-obra do setor. No Brasil, assim como em outros países, a indústria moveleira caracteriza-se pela organização em pólos regionais, sendo os principais: Grande São Paulo (SP), Bento Gonçalves (RS), São Bento do Sul (SC), Arapongas (PR), Ubá (MG), Votuporanga e Mirassol (SP). Possui aproximadamente 13.500 empresas: cerca de 10 mil microempresas (até 15 funcionários), 3 mil pequenas empresas (de 15 até 150 funcionários) e apenas 500 empresas de porte médio (acima de 150 funcionários). Na sua quase totalidade, são empresas familiares, de capital inteiramente nacional.

No Estado do Paraná, tem-se o pólo moveleiro de Arapongas, que surgiu nos anos 60 e atualmente é o principal do país, contando com cerca de 140 empresas e 5 mil trabalhadores, além de gerar mais de $60 \%$ das receitas do município. Esse pólo está voltado para a produção de móveis populares, destacando-se o segmento de estofados, que conta com mais de 40 empresas, entre elas a Simbal, a maior produtora de estofados do país, fundada em 1962.

Constitui o objetivo principal deste artigo: a) obter os multiplicadores da matriz de contabilidade social do Estado do Paraná; b) identificar os efeitos do choque de demanda por atividade sobre o segmento de Madeira e Mobiliário e de Papel e Gráfica; c) identificar os efeitos do choque de demanda nos dois segmentos sobres as outras atividades. 
Determinação dos multiplicadores da matriz de contabilidade social, da indústria de base florestal paranaense - 1998

\section{Metodologia}

A matriz de contabilidade social (MCS) é um sistema de dados usado para a análise de políticas econômicas. Como sistema de dados, é compreensiva e desagregada e inclui estimativas de transações dos setores, das instituições e dos agentes econômicos. Permite a identificação das relações de compra e venda, além de fornecer uma classificação e um esquema organizacional para os dados úteis ao planejamento econômico. Um analista interessado em entender como a estrutura de produção influencia na distribuição de Renda Nacional pode obter informações úteis estudando a MCS.

A MCS incorpora explicitamente várias relações cruciais entre as variáveis, como a estrutura da distribuição da produção, da distribuição de renda doméstica e dos fatores da distribuição de renda.

\subsection{Multiplicadores da matriz de contabilidade social}

Quando há excesso de fatores de produção, como, por exemplo, trabalhadores desempregados, por meio dos multiplicadores contábeis da MCS é possível estimar o efeito de uma mudança das variáveis exógenas. Como mudança das variáveis exógenas entende-se um crescimento das exportações ou nos investimentos ou um aumento dos gastos do governo. O incremento nas variáveis endógenas gera elevação da produção sem causar efeitos nos preços.

O total dos efeitos diretos e indiretos - resultante de uma injeção direcionada nas contas endógenas - sobre a produção das empresas, sobre a remuneração dos fatores de produção e a renda das famílias é estimado por meio dos multiplicadores da MCS. Thorbecke (1998) exemplifica como o efeito multiplicador propaga-se na economia: um estudo público de viabilidade de uma fazenda verificou a necessidade da construção de uma estrada para comercialização dos produtos. A construção da estrada vai necessitar de trabalhadores inexperientes como os trabalhadores rurais (bóias-frias) e os pequenos proprietários rurais. Esses dois grupos socioeconômicos de trabalhadores terão incremento na sua renda e, conseqüentemente, aumentarão sua demanda por alimentos. O crescimento subseqüente em produção de comida leva 
à necessidade de emprego adicional e incrementos de renda para esses grupos, e assim por diante, até que o processo multiplicador amorteça.

O Quadro 1 apresenta uma MCS simplificada, com três contas endógenas (Atividades, Fatores e Instituições) e uma conta exógena. As três contas exógenas foram combinadas juntas. As injeções referentes ao aumento do dispêndio do governo, do investimento e das exportações, respectivamente, são consolidadas em três vetores: $\mathrm{f}_{1}, \mathrm{f}_{2}, \mathrm{f}_{3}$.

Quadro 1 - Esquema simplificado da MCS

\begin{tabular}{|c|c|c|c|c|c|c|c|}
\hline & \multicolumn{3}{|c|}{ CONTAS ENDÓGENAS } & \multirow{2}{*}{\multicolumn{2}{|c|}{ EXÓGENAS }} \\
\hline & & & $\begin{array}{c}\text { Atividades de } \\
\text { Produção }\end{array}$ & $\begin{array}{c}\text { Fatores } \\
2 \\
\end{array}$ & $\begin{array}{c}\begin{array}{c}\text { Instituições } \\
\text { (Famílias e } \\
\text { Empresas) }\end{array} \\
3\end{array}$ & & \\
\hline \multirow{3}{*}{ 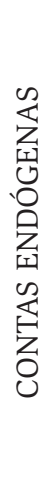 } & $\begin{array}{l}\text { Atividades de } \\
\text { Produção }\end{array}$ & 1 & $\mathrm{~T}_{11}$ & 0 & $\mathrm{~T}_{13}$ & $\mathrm{f}_{1}$ & $\mathrm{y}_{1}$ \\
\hline & Fatores & 2 & $\mathrm{~T}_{21}$ & 0 & 0 & $\mathrm{f}_{2}$ & $\mathrm{y}_{2}$ \\
\hline & $\begin{array}{l}\text { Instituições } \\
\text { (Famílias e } \\
\text { Empresas) }\end{array}$ & 3 & 0 & $\mathrm{~T}_{32}$ & $\mathrm{~T}_{33}$ & $\mathrm{f}_{3}$ & $\mathrm{y}_{3}$ \\
\hline 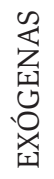 & $\begin{array}{l}\text { Soma das } \\
\text { outras contas }\end{array}$ & 4 & $\mathrm{f}_{1}{ }^{\prime}$ & $\mathrm{f}_{2}$, & $\mathrm{f}_{3}{ }^{\prime}$ & $\mathrm{F}$ & $\mathrm{Y}_{\mathrm{x}}$ \\
\hline \multicolumn{2}{|c|}{ TOTAL } & 5 & $y_{1}^{\prime}$ & $y_{2}{ }^{\prime}$ & $\mathrm{y}_{3}^{\prime}$ & $Y_{n}$ & \\
\hline
\end{tabular}

Fonte: Thorbecke (1998, p.301) (tradução livre)

O primeiro vetor $\left(\mathrm{f}_{1}\right)$ representa o total exógeno da demanda para as atividades de produção que resultam de consumo do governo, demanda de investimento e exportação. Semelhantemente, $\mathrm{f}_{2}$ e $\mathrm{f}_{3}$ corres- 
pondem, respectivamente, ao total exógeno da demanda para fatores (e conseqüentemente injeção de renda para recompensar fatores) e ao total de renda exógeno, resultante para diferentes instituições, como subsídios do governo e remessas para o exterior. Igualmente, $\mathrm{f}_{\mathrm{i}}$ refere-se a importações, poupança e tributação.

A lógica do esquema do Quadro 1 demonstra que uma mudança nas contas exógenas (o fi's), determina, mediante sua interação dentro da matriz de MCS, os fluxos do consumo intermediário, da renda e do consumo das famílias das contas endógenas. O valor da produção corresponde ao vetor $\mathrm{y}_{1}$; a renda dos fatores, ao vetor $\mathrm{y}_{2}$; e a renda das instituições, ao vetor $\mathrm{y}_{3}$.

Definindo-se como $\mathbf{T}$ a matriz de transações do MCS, em que tij corresponde ao pagamento da conta coluna j para conta linha i. A matriz de coeficientes técnicos diretos da MCS é construída a partir da matriz $\mathbf{T}$, dividindo-se cada célula de cada coluna de $\mathbf{T}$ pelo somatório da coluna:

$$
\text { Aij }=\mathrm{ti}, \mathrm{j} / \mathrm{yj}
$$

A matriz dos coeficientes técnicos diretos é representada da seguinte forma na estrutura matricial:

$$
A n=\left[\begin{array}{ccc}
A 11 & 0 & A 13 \\
A 21 & 0 & 0 \\
0 & A 32 & A 33
\end{array}\right]
$$

Descrevendo cada conjunto de matriz que compõe a matriz An, tem-se:

a) O subconjunto A11 é o conjunto de coeficientes de produção. E corresponde ao valor do aumento do fornecimento de insumo pelo aumento de uma unidade monetária nas variáveis exógenas;

b) O subconjunto A21 é o conjunto de coeficientes técnicos dos valores adicionados e refere-se ao valor aumento do valor adicionado pelo aumento de uma unidade monetária nas variáveis exógenas;

c) Os coeficientes do subconjunto A13 mostram a participação de cada atividade na composição das compras de grupo domésticas nas despesas totais;

d) Os coeficientes do subconjunto A33 representam as transferên- 
cias de renda para outros grupos domésticos por unidade monetária de renda;

e) Os coeficientes do subconjunto A32 demonstram a participação das famílias, empresas e dos impostos na renda gerada.

No Quadro 1, conforme se observa na matriz, o total da renda (Yn) é dado pela seguinte fórmula:

$\mathrm{Yn}=\mathrm{An} \mathrm{Yn}+\mathrm{f}$

A equação 2.1.3 pode ser assim reescrita:

$Y n=(I-A n)^{-1} f$

Em que:

Yn $\quad=$ Valor das rendas;

I $\quad=$ Matriz identidade;

An $=$ Coeficiente técnico direto;

$(\mathrm{I}-\mathrm{An})^{-1} \quad=$ Matriz dos multiplicadores contábeis;

$\mathrm{f}=$ Somatório das variáveis exógenas.

Na equação (2.1.4), $\mathrm{Y}_{\mathrm{n}}$ pode ser dividido em $\mathrm{Y}_{1}$, que representa a produção total de bens e serviços; $Y_{2}$, que demonstra o total do valor adicionado distribuído entre os fatores de produção; e $\mathrm{Y}_{3}$, que corresponde ao total da renda apropriada pelas instituições. Assim, pode-se reescrever a equação (2.1.3) de forma desagregada:

$$
\begin{array}{llll}
Y_{1}=A_{11} Y_{1} & & +A_{13} Y_{2} & +f_{1} \\
Y_{2}=A_{21} Y_{1} & & & +f_{2} \\
Y_{3}= & A_{32} Y_{2} & +A_{33} Y_{3} & +f_{3}
\end{array}
$$

Reescrevendo a fórmula (2.1.5), tem-se:

$$
\begin{aligned}
& Y_{1}=\quad\left(I-A_{11}\right)^{-1} A_{13} Y_{3}+\left(I-A_{11}\right)^{-1} f_{1} \\
& Y_{2}=A_{21} Y_{1} \\
& Y_{3}=\quad\left(I-A_{33}\right)^{-1} \\
& +\mathrm{f}_{2} \\
& +\left(I-A_{33}\right)^{-1} f_{3}
\end{aligned}
$$

Uma injeção por meio do aumento das exportações, dos gastos do 
governo ou investimentos $\left(\mathrm{f}_{1}\right)$ resulta em um crescimento adicional da produção em $\left(\mathrm{I}-\mathrm{A}_{11}\right)^{-1} \mathrm{f}_{1}$. Também é necessário o emprego de novos fatores de produção, ocasionando o incremento do valor adicionado $\left(\mathrm{A}_{21} \mathrm{f}_{1}\right)$, mais fatores exógenos recebidos de outras regiões ou países ou do governo, denominados $\mathrm{f}_{2}$. Então:

$$
Y_{2}=A_{21} Y_{1}+f_{2}
$$

Em seguida, as instituições recebem renda $\left(\mathrm{I}-\mathrm{A}_{33}\right)^{-1} \mathrm{~A}_{32} \mathrm{Y}_{2}$, baseada na propriedade dos fatores de produção. Também ocorre a transferência entre as instituições, como subsídio do governo $\left(\mathrm{I}-\mathrm{A}_{33}\right)^{-1} \mathrm{f}_{3}$. Dessa forma:

$$
Y_{3}=\left(I-A_{33}\right)^{-1} \quad A_{32} y_{2}+\left(I-A_{33}\right)^{-1} f_{3}
$$

Finalizando, fecha-se o triângulo, as instituições aumentam sua demanda, resultando em $\mathbf{n}$ produção de novos produtos, devido ao incremento da renda. Esse fluxo é representado pela seguinte fórmula:

$$
Y_{1}=\left(I-A_{11}\right)^{-1}\left(A_{13} y_{3}+f_{3}\right)
$$

Os multiplicadores do MCS (I - An)-1 diferem dos multiplicadores de Leontief $\left(\mathrm{I}-\mathrm{A}_{11}\right)^{-1}$ pelo fato de o primeiro incluir a renda dos fatores de produção e o nível de renda, e em última instância, o padrão de despesas resultante aberto em produto ou atividade gera multiplicadores mais amplos, se comparados com os multiplicadores de Leontief ${ }^{3}$, que são mais limitados, devido a não incorporarem o efeito renda. Em outras palavras, os multiplicadores da matriz de Leontief englobam os multiplicadores diretos e indiretos. Os multiplicadores da MCS, são resultantes da soma dos multiplicadores diretos e indiretos mais os multiplicadores do efeito renda, que decorrem do aumento da renda das famílias.

${ }^{3} \mathrm{O}$ aumento da demanda final ocasiona, além dos efeitos diretos na produção de insumos, efeitos indiretos, ou seja, ocorre a primeira rodada de compras, a segunda rodada, a terceira rodada, e assim por diante. A fim de determinar os efeitos diretos e indiretos, faz-se necessário utilizar a matriz inversa de Leontief, que no presente trabalho é calculada pela fórmula $\mathrm{Y}=\left(\mathrm{I}-\mathrm{A}_{11}\right)^{-1}$ 


\section{Discussão dos resultados}

Na abordagem global da economia paranaense, utilizando-se os multiplicadores da MCS, pode-se fazer uma visualização dos efeitos das injeções tanto no encadeamento para trás como para frente. Os efeitos para trás referem-se à soma das colunas dos multiplicadores contábeis das 41 atividades. O resultado demonstra o incremento das compras de consumo intermediário por atividade econômica do aumento de uma unidade monetária nas variáveis exógenas. Já os efeitos para frente revelam quanto cada atividade econômica fornece de consumo intermediário decorrente de uma unidade monetária nas variáveis exógenas.

Os Gráficos 1 e 2 dão a conhecer os efeitos para trás de uma injeção no total da economia, destacando-se nos três primeiros lugares as atividades de Abate de Animais (26), Indústria de Açúcar (28) e Fabricação de Óleos Vegetais (29). Essas atividades indicam o perfil agroindustrial do Estado do Paraná, de 1998.

No que se refere à estrutura da indústria de produtos alimentares, Nojima (1999, p.80) faz a seguinte observação: "Uma avaliação preliminar dos anos 90, demonstra, em princípio, a manutenção daquela estrutura industrial, com o predomínio de $28,2 \%$ de beneficiamento e moagem de grão, $29 \%$ de carne e 6,2\% de óleo refinado (exclusive o bruto) no valor adicionado do gênero produtos alimentares em 1997, em detrimento de massas, doces, etc., com $9 \%$."

Com relação aos efeitos para frente, em outras palavras, ao fornecimento de insumos e serviços intermediários, seria de se esperar que a atividade de Comércio (34) e Agropecuária (1) se localizassem nos primeiros lugares. O peso do Setor Comércio na economia paranaense é explicado por dois fatores:

a) O fornecimento por parte do comércio atacadista de insumos para o Setor Agrícola;

b) A comercialização da produção agrícola que é contabilizada dentro da atividade comércio.

A atividade Agropecuária é o principal fornecedor de matérias-primas para o Setor Agroindustrial, este fortemente vinculado aos principais setores demandantes - Abate de Animais (26), Indústria de Açúcar (28) e Fabricação de Óleos Vegetais (29). Segundo Bittencourt (2000), a agropecuária paranaense teve grandes incrementos de produção e pro- 
dutividade nos anos 90, mesmo com todas as dificuldades por que passou a economia. Grande parte dos produtos agrícolas teve crescimento de produção, contribuindo para que o Paraná se tornasse o maior produto de grãos do país. Conforme Suzuki (2001), na década de 1990 ocorreu a redução dos financiamentos oficiais para o setor, entretanto a produção de grãos aumentou, comprovando a elevação da eficiência setorial na utilização dos recursos disponíveis.

A atividade Aluguel de Imóveis (39) ficou em terceiro lugar no encadeamento para frente. Uma das diferenças entre o multiplicador contábil (I-An) $)^{-1}$ e o multiplicador de Leontief $\left(\mathrm{I}-\mathrm{A}_{11}\right)^{-1}$ é que o primeiro engloba o consumo das famílias no cálculo dos multiplicadores. $\mathrm{O}$ fato de o Aluguel de Imóveis ter o maior peso no consumo das famílias faz com que essa atividade apresente um elevado efeito multiplicador. Todavia, falta ressaltar em que consiste a atividade Aluguel e por que possui elevado peso dentro do consumo das famílias. Isso se justifica pelo tratamento dado a essa atividade nas Contas Regionais do Instituto Brasileiro de Geografia e Estatística (IBGE).

Em relação ao setor de aluguéis de imóveis, para as Contas Nacionais estão incluídas nesta atividade os aluguéis recebidos por particulares pela cessão de seus imóveis, sob regime de aluguel, para terceiros e, o valor do aluguel imputado aos residentes em moradia própria.

O valor do aluguel imputado de casas próprias é incluído no conceito de produção das Contas Nacionais para conciliar este conceito com o de formação de capital e de consumo final das famílias. Segundo as Contas Nacionais, por definição, toda produção da construção civil de imóveis residenciais ou comerciais é destinada à formação bruta de capital fixo da economia.

A formação bruta de capital fixo consiste no valor de investimento em bens de capital destinados à produção de outros bens ou serviços. De acordo com este conceito, todo investimento na compra de um bem de capital tem, como contrapartida, a produção de um serviço denominado "Serviço da Formação Bruta de Capital”, que, por sua vez, gera uma renda para o proprietário do bem de capital. (IBGE, 2002, p.46). 


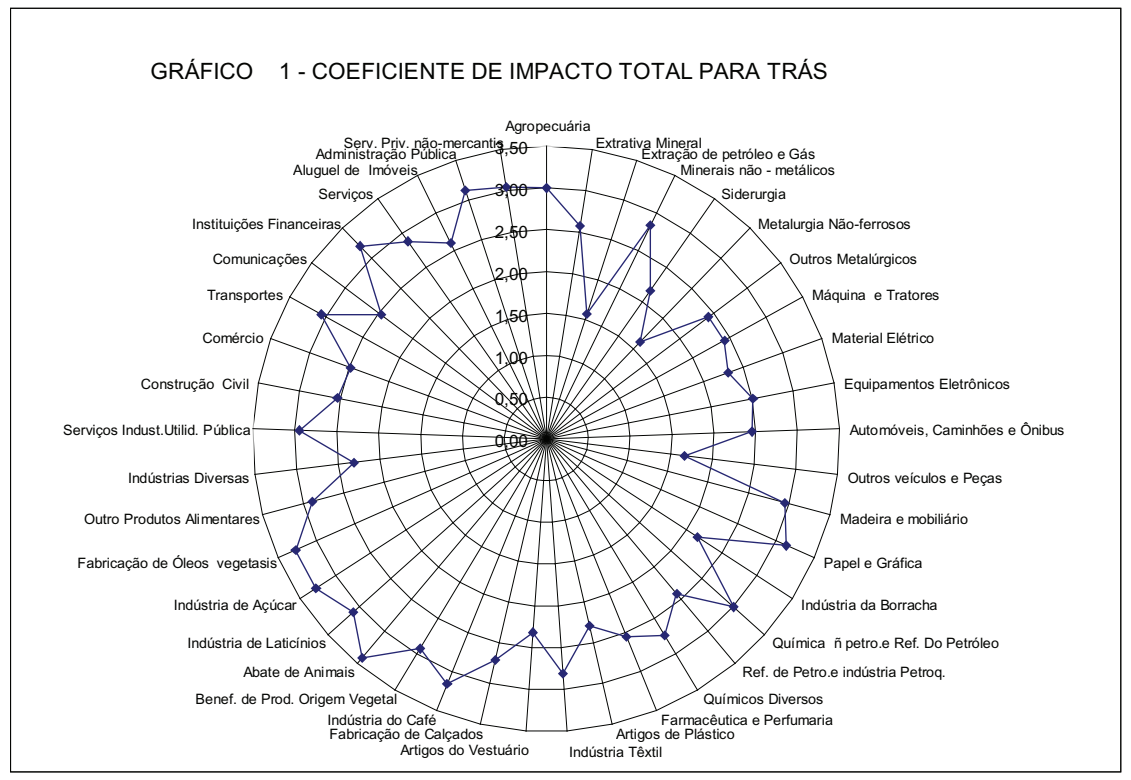

Fonte: Tabela A.1

\section{GRÁFICO 2 - COEFICIENTE DE IMPACTO TOTAL PARA FRENTE}

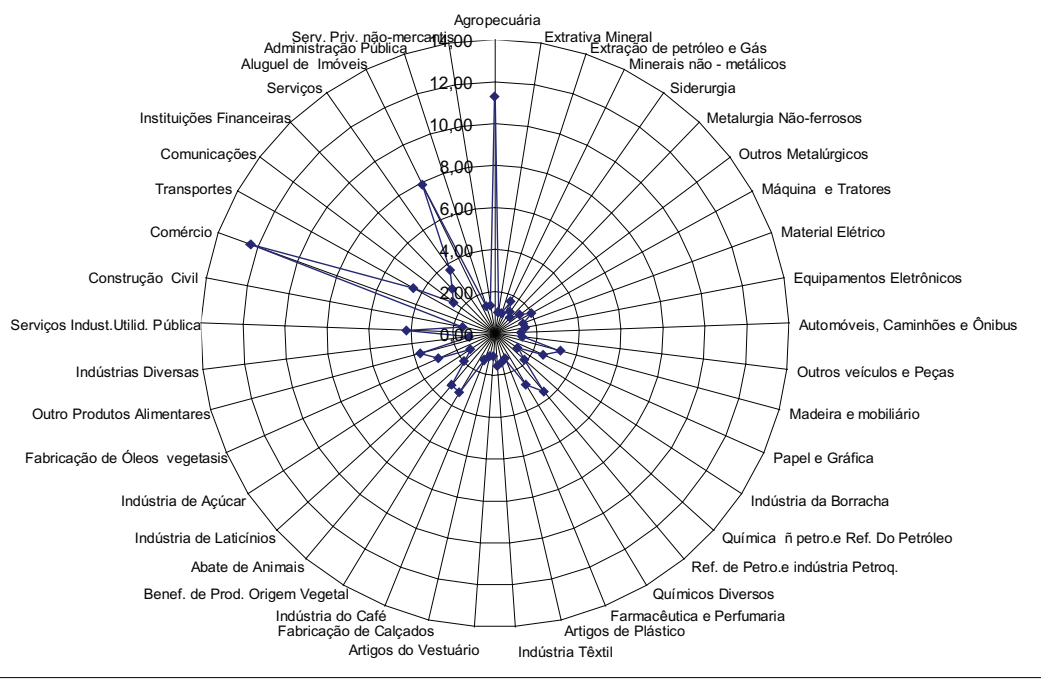

RER, Rio de Janeiro, vol. 44, no 04, p. 731-750, out/dez 2006 - Impressa em dezembro 2006 
A renda gerada pela propriedade de um imóvel é o aluguel imputado, fazendo com que a atividade Aluguel tenha um peso significativo entre as atividades econômicas paranaenses. O aluguel imputado é consumido pelas famílias, resultando no maior multiplicador contábil para essa atividade.

Com relação à indústria de base florestal, indústria de Madeira e Mobiliário (13) e de Papel e Papelão (14), por meio da Matriz de Multiplicadores Contábeis foi obtido o choque de demanda por atividade sobre a atividade de Madeira e Mobiliário e de Papel e Gráfica. Também foi calculado o choque de demanda das duas atividades sobres as demais. $\mathrm{O}$ primeiro choque foi encontrado por meio da linha das atividades. Refere-se, então, ao fornecimento intermediário devido à injeção de uma unidade monetária nas variáveis exógenas. O segundo choque foi obtido na coluna das atividades. Demonstra a compra intermediária das atividades pela injeção de uma unidade monetária nas variáveis exógenas.

Os Gráficos 3 e 4 mostram os efeitos de uma injeção nas variáveis exógenas sobre as atividades Madeira e Mobiliário (13) e de Papel e Papelão (14). Em ambas, o choque mais intenso foi dentro do próprio setor. Observa-se que a atividade de Madeira e Mobiliário tem maiores ligações com aquelas ligadas ao Setor Terciário, como é o caso dos serviços Privado e Não-Mercantis (41), Administração Pública (40) e Instituições Financeiras (37). Como destaca Gorini (1998), a indústria nacional de móveis localiza-se principalmente nas regiões Sul e Sudeste, com cerca de $88 \%$ da produção doméstica proveniente dos estados de São Paulo, Rio Grande do Sul, Santa Catarina, Paraná e Minas Gerais. O segmento produtor de compensados no Brasil, como observa Macedo (1997), é constituído, predominantemente, por pequenas e médias empresas, que possuem cerca de 400 fábricas, concentradas em sua maioria na Região Sul, em especial, no Estado do Paraná.

Já o segmento de Papel e Papelão tem suas maiores ligações com atividades que necessitam de materiais gráficos e embalagens, como Outros Produtos Alimentares (30), Administração Pública (40), Fabricação de Calçados (23), Instituições Financeiras (37) e Farmacêutica e Perfumaria (19). Os estados do Paraná, Santa Catarina e São Paulo são responsáveis por 81 \% da produção de papel de embalagem no país. Com referência a papel para imprensa, o Paraná é o único produtor no Brasil (MATTOS, 1999). 
GRAFICO 3 - EFETOO DE UM CHOQUE DE DEMANDA POR ATIVIDADE SOBRE O SEGMENTO DE MADEIRA E MOBILIÁRIO, NO PARANÁ - 1998

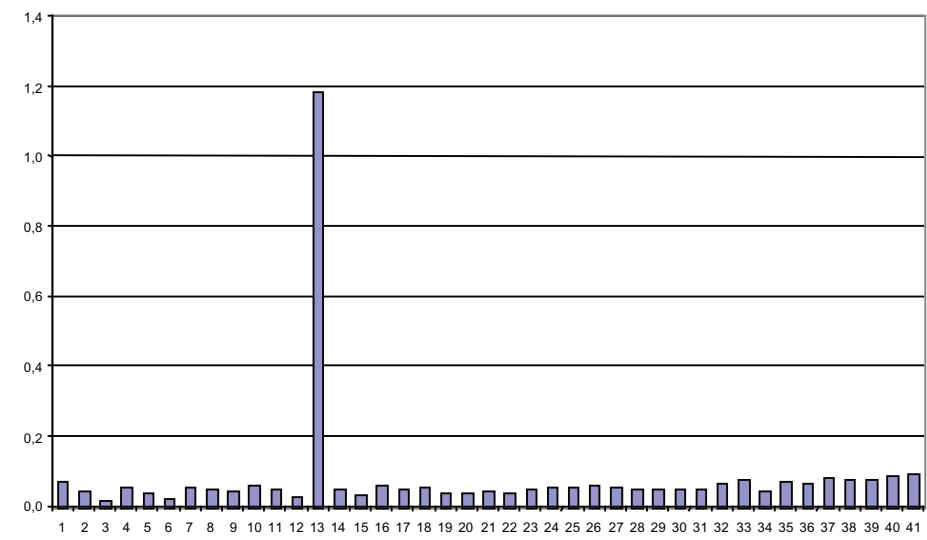

Fonte: Tabela A.1

GRÁFICO 4 - EFETTO DE UM CHOQUE DE DEMANDA POR ATMIDADE SOBRE O SEGMENTO DE PAPEL ECELULOSE, NO PARANÁ - 1998

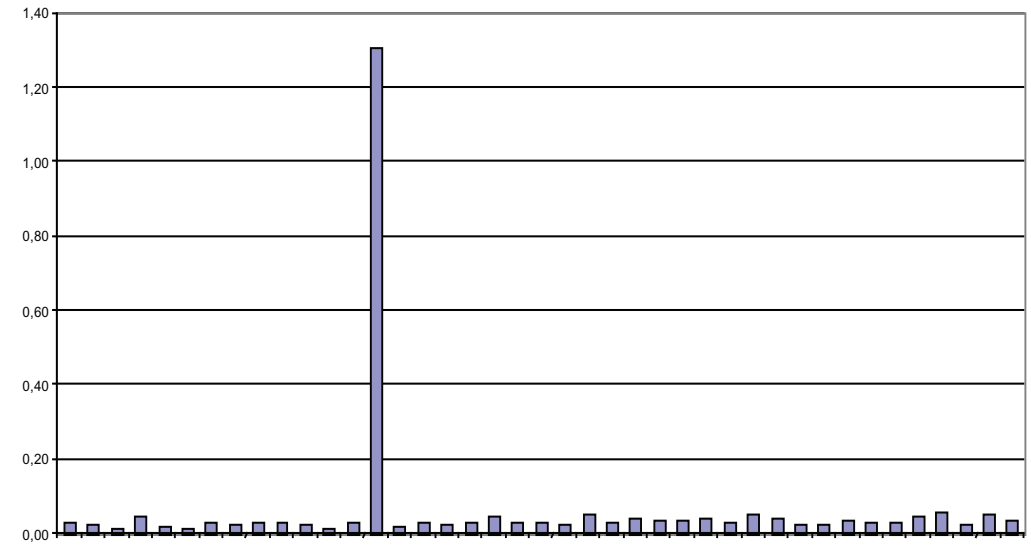

Fonte: Tabela A.1

Os Gráficos 5 e 6 demonstram os efeitos de uma injeção na atividade Madeira e Mobiliário (13) e de Papel e Gráfica (14) sobre as outras atividades. O segmento de Papel e Gráfica possui um encadeamento interno intenso dentro da própria atividade, que é a de Madeira e Mobiliário, visto que a sua cadeia produtiva é mais fechada dentro da própria atividade. Em ambas as atividades, as ligações estão relacionadas com o fornecimento de matérias-primas da Agropecuária (1) e do Comércio (34). 
Determinação dos multiplicadores da matriz de contabilidade social, da indústria de base florestal paranaense - 1998

GRÁFICO 5 - EFEITO DE UM CHOQUE DE DEMANDA DA ATIVIDADE DE MADEIRA E SOBRE OUTRAS ATIVIDADES, NO PARANÁ - 1998

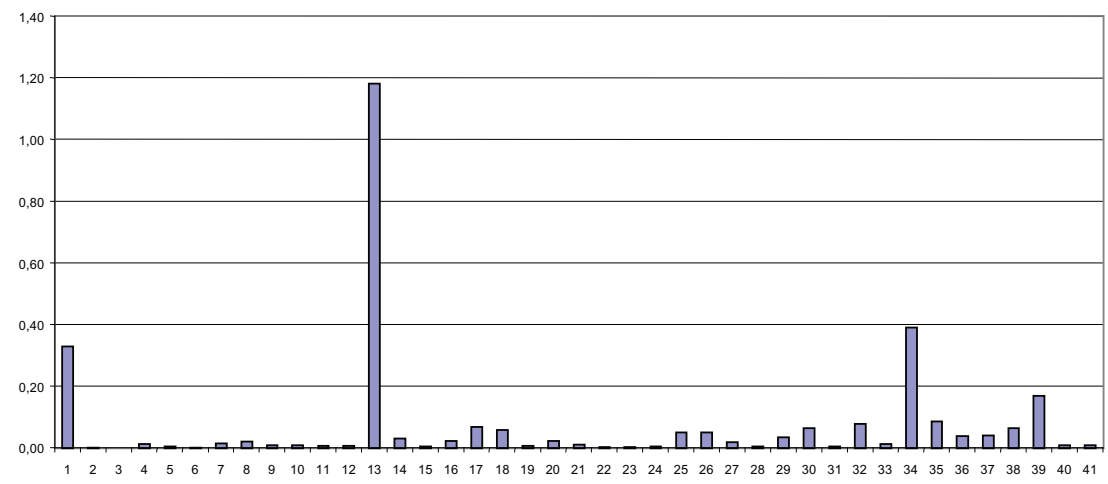

FONTE: Tabela A.1

GRÁFICO 6 - EFEITO DE UM CHOQUE DE DEMANDA DA ATIVIDADE DE PAPEL E CELULOSE OUTRAS ATIVIDADES, NO PARANÁ - 1998

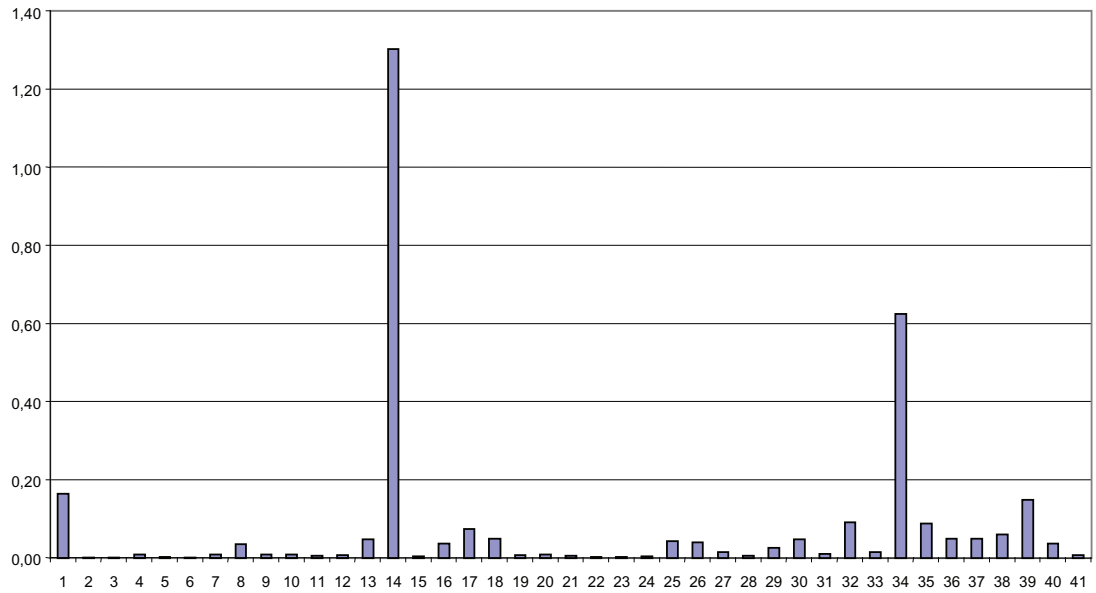

FONTE: Tabela A.1

\section{Considerações finais}

Apesar da agregação das atividades econômicas da matriz de contabilidade social paranaense, foi possível identificar os principais impactos decorrentes do aumento da demanda final da indústria de base 
florestal como demandante e ofertante de insumos intermediários. A partir desses multiplicadores apresentados nesse artigo, é possível estimar outros, tais como, multiplicador de emprego, renda, produção e impostos complexos. A matriz e os multiplicadores, obtidos neste trabalho estão à disposição para os estudantes e pesquisadores, bastando solicitar aos autores. O objetivo é incentivar novas pesquisas.

Finalizando, o Instituto Brasileiro de Geografia e Estatística está disponibilizando uma nova pesquisa denominada Pesquisa Industrial Anual. Através dessa publicação é possível que os órgãos estaduais de pesquisa, como por exemplo, o Instituto Paranaense de Desenvolvimento Econômico e Social (IPARDES), construa uma matriz de insumoproduto ou de contabilidade social regional atualizada, com a atividade industrial desagregada. Assim será possível, por exemplo, estudar a indústria de base florestal, com um nível de desagregação maior e com dados mais atualizados.

\section{Referências Bibliográficas}

BITTENCOURT, Maurício Vaz Lobo Bittencourt; LOPES, Melissa G. Ferreira da S. Lopes. Desempenho da agricultura paranaense nos anos 90. Texto para discussão $n^{\circ}$ 08/2000 - Curso de Mestrado em Desenvolvimento Econômico - UFPR. 28p.

CABALLERO NUÑEZ, B. E.; C. H. P.; KURESKI, R. A matriz de contabilidade social do Paraná - 1998. [S.I.: s.n.], 2004.

GORINI, Ana Paula Fontenelle. Panorama do setor moveleiro no Brasil, com ênfase na competitividade externa a partir do desenvolvimento da cadeia industrial de produtos sólidos de madeira. Rio de Janeiro: BNDES, setorial n.8, p.3-57, set. 1998.

INSTITUTO BRASILEIRO DE GEOGRAFIA E ESTATÍSTICA. Contas regionais do Brasil - 2000. Departamento de Contas Nacionais. Rio de Janeiro: IBGE, 2002. 119p.

MACEDO, Angela Regina Pires Macedo; ROQUE, Carlos Alberto Lourenço Roque. Painéis de madeira. Rio de Janeiro: BNDES, setorial n.6, p.117-132, set. 1997. 
MATTOS, René Luiz Grion; VALENÇA, Antonio Carlos de Vasconcelos. A reestruturação do setor de papel e celulose. Rio de Janeiro: BNDES, setorial n.10, p.253-267, set. 1999.

NOJIMA, Daniel. Panorama, tendência e competitividade da indústria de alimentos e de bebidas no Paraná. Revista Paranaense de Desenvolvimento, Curitiba: IPARDES, n.82, p.79-87, 1994.

PALADINO, G.G. Papel, técnica e capital. Estudo sobre a evolução e mutação nos processos de trabalho e de produção do papel e análise do desenvolvimento do setor papeleiro no Brasil. Curitiba, 1985. 364 p. Dissertação (Mestrado) - CEDEPLAR/UFMG.

SANTOS, Ronaldo Marcos dos; PAMPLONA, Telmo; FERREIRA, Marcos José Barbieri. Design na indústria brasileira de móveis. UNICAMP Campinas, março 1999. Disponível em: < http://www.abimovel.org. br/download.htm > . Acesso em: janeiro 2004.

SUZUKI, Julio Takeshi Suzuki Júnior. A evolução da agricultura paranaense. Análise Conjuntural, Curitiba, v.23, n.7-8, p.16-17, jul./ago. 2001.

THORBECKE, Erik. Social accounting matrices and social accounting analiysis. Methods of interregional and regional analysis. England: Ashgate, 1998. 


\section{Anexo 1}

Tabela A .1 - Multiplicador da matriz de contabilidade social do paraná $-1998$

\begin{tabular}{|c|c|c|c|c|c|c|c|c|c|c|c|c|c|c|c|c|c|c|c|c|}
\hline & & & & 4 & 05 & 06 & 07 & 08 & 9 & 10 & 11 & 12 & 13 & & 15 & 16 & 17 & 18 & 19 & 20 \\
\hline 1 & & & & & & & & & & & & & & & & & & & & \\
\hline 2 & & & & & & & & & & & & & & & & & & & & \\
\hline 3 & 00 & & & & & & & & & & & & & & & & & & 00 & \\
\hline 4 & & & & & & & & & & & & & & & & & & & 02 & 0,01 \\
\hline 5 & ,00 & 00 & 00 & & 08 & & & & & & & & & & 00 & & .00 & ,01 & 00 & 0,00 \\
\hline 6 & & & & & & & & & & & & & & & & & & & & 0,00 \\
\hline 7 & 0 & & & & & & & & & & & & & & & & & & & 0,01 \\
\hline 8 & & 06 & & & & & & & & & & & & & & & & & & 0,02 \\
\hline 9 & 0,01 & 0,01 & & & 1,08 & & & & & & & & & & & & & & & 0,01 \\
\hline 10 & 0,01 & 0,01 & 0,00 & 0,01 & ,08 & 0,00 & & 0,01 & & 10 & & & & & & & 01 & 11 & 01 & 0,01 \\
\hline 11 & 0,01 & 01 & & & & & & & & & & & & & & & & & & 0,00 \\
\hline 12 & 0,01 & 01 & 0 & 01 & 08 & 00 & & & & 0 & & & & & & & & & 00 & 0,00 \\
\hline 13 & & & & & & & & & & & & & & & & & & & & 0,04 \\
\hline 14 & 0 & & & & & & & & & & & & & & & & & & & 0,03 \\
\hline 15 & & & & & & & & & & & & & & & & & & & & 1,00 \\
\hline 16 & 0,02 & & & & & & & & & & & & & & & & & & & ,02 \\
\hline 17 & 0,07 & & 0,0 & & 10 & ( & & & & 0 & & & & & & & 10 & & 05 & 0,14 \\
\hline 18 &, 14 & 05 & & & & & & & & & & & & & & & & & & 0,03 \\
\hline 19 & & & & & & & & & & & & & & & & & & & & 0,01 \\
\hline 20 & & & & & & & & & & & & & & & & & & & & 1,02 \\
\hline 21 & & & & & & & & & & & & & & & & & & & & \\
\hline 22 & & & & & & & & & & & & & & & & & & & & 00 \\
\hline 23 & & & & & & & & & & & & & & & & & & & &, 00 \\
\hline 24 & & & & & & & & & & & & & & & & & & & & 0,00 \\
\hline 25 & ,07 &, 04 & & c & & & & & & 0,0 & & & & & & & & & & 0,04 \\
\hline 26 & & & & & & & & & & & & & & & & & & & & 0,04 \\
\hline 27 & 0 & & & & & & & & & & & & & & & & & & & 0,01 \\
\hline 28 & & & & & & & & & & & & & & & & & & & & 0,00 \\
\hline 29 & & & & & & & & & & & & & & & & & & & & \\
\hline 30 & 0,13 & 0,05 & 0,0 & 0,06 & 1,0 & 0,02 & & & & 0,05 & & & & & 0,04 & & 0,06 & & 0,04 & 0,04 \\
\hline 31 & & & & & & & & & & & & & & & & & & & & \\
\hline 32 & 0,08 & 0,09 & & & & & & & & & & & & & & & 0,07 & & & 0,06 \\
\hline 33 & ,01 & & & & & , & & & & 0,0 & & & & & & & 0,01 & & 01 & 0,01 \\
\hline 34 & & & & & & & & & & & & & & & & & & & & 0,27 \\
\hline 35 & 0 &, 09 & 0,0 & & & & & & & 0,0 & 0, & & & & 0,06 & $0, \mathrm{C}$ & 0,10 & 0,0 & 0,08 & 0,06 \\
\hline 36 & & & & & & & & & & & & & & & & & & & & 0,03 \\
\hline 37 & 0,05 & 0,06 & & & 1,08 & & & & & 0,04 & & & & & & & & & 0,03 & 0,03 \\
\hline 38 & & & & & & & & & & & & & & & & & & & & 0,0 \\
\hline 39 & 0,22 & 0,15 & & 0,18 & & & & & & & & & & & & & & & & 0,13 \\
\hline 40 & 0,01 & 0,01 & 0,00 & 0,01 & 1,08 & 0,0 & 0,01 & 0,0 & 0,01 & 0,0 & 0,01 & & & 0,0 & 0,00 & & 0,01 & & 0,01 & 0,01 \\
\hline 41 & 0,01 & 0,01 & 0,00 & & 1,08 & 0,00 & 0,01 & & & & & & & & 0,01 & & 0,01 & & 0,01 & 0,01 \\
\hline 42 & 0,32 & 0,29 & 0,10 & & & & & & & & & & & & 0,20 & & 0,21 & & 0,22 & 0,25 \\
\hline 43 & 1,2 & & & & & & & & & & & & & & & & ,92 & & 0,57 & 0,59 \\
\hline 44 & 1,21 & 0,75 & 0,29 & 0,94 & 1,08 & 0,38 & 0,87 & 0,81 & 0,65 & 0,76 & 0,75 & 0,38 & 0,88 & 0,69 & 0,59 & 1,02 & 0,88 & 0,87 & 0,63 & 0,67 \\
\hline
\end{tabular}

Fonte: Matriz de Contabilidade Social do Paraná - 1998

Nota: Cálculo realizado pelos autores 
748 - Determinação dos multiplicadores da matriz de contabilidade social, da indústria de base florestal paranaense - 1998

\begin{tabular}{|c|c|c|c|c|c|c|c|c|c|c|c|c|c|c|c|c|c|c|c|c|c|c|c|}
\hline 21 & 22 & 23 & 24 & 25 & 26 & 27 & 28 & 29 & 30 & 31 & 32 & 33 & 34 & 35 & 36 & 37 & 38 & 39 & 40 & 41 & 42 & 43 & 44 \\
\hline 0,20 & & & & & & & & & & & & & 0,15 & 0,22 & 0,20 & & 0,27 & 0,23 & 0,29 & 0,30 & 0,30 & 0,23 & 0,31 \\
\hline 0,00 & & & & & & & & & & & & & & & & & & & & & & & \\
\hline 0,00 & 0,00 & 00 & 00 & & 00 & & ,00 & 0,00 & 1,00 & 0,00 & 0,00 & 0,00 & 0,00 & 0,00 & 0,00 & 0,00 & 0,00 & 0,00 & 0,00 & 0,00 & 0,00 & 0,00 & 0,00 \\
\hline 0,01 & 00 & 01 & 01 & 01 & 01 & 01 & ,01 & 0,01 & ,02 & 0,01 & 01 & ,11 & 0,01 & 0,01 & 0,01 & 0,01 & 0,01 & 0,01 & 0,01 & 0,01 & 0,01 & 0,01 & 0,01 \\
\hline 0,00 & 00 & 0,00 & 00 & 00 & 00 & & .00 & 0,00 & 0,00 & 0,00 & 0,00 & 0,01 & 0,00 & 0,00 & 0,00 & 0,00 & 0,00 & 0,00 & 0,00 & ,00 & 0,00 & 1,00 & 0,00 \\
\hline 0,00 & 0,00 & 0,00 & 0,00 & 0,00 & 0,00 & 0,00 & 0,00 & 0,00 & 0,00 & 0,00 & 0,00 & 0,00 & 0,00 & 0,00 & 0,00 & 0,00 & 0,00 & 0,00 & 0,00 & 0,00 & 0,00 & 0,00 & 0,00 \\
\hline 0,01 & 0,01 & 0,01 & 0,01 & & 0,01 & 0,01 & 0,01 & 0,02 & 0,01 & 0,01 & 0,01 & 0,03 & 0,01 & 0,01 & 0,01 & 0,01 & 0,01 & 0,01 & 0,01 & 0,01 & 0,01 & 0,01 & 0,01 \\
\hline 0,03 & 0,01 & 0,02 & 0,01 & 0,02 & 0,02 & 0,02 & 0,07 & 0,02 & 0,02 & 0,02 & 0,05 & 0,02 & 0,01 & 0,02 & 0,02 & 0,02 & 0,02 & 0,01 & 0,02 & 0,02 & 0,02 & 0,01 & 0,02 \\
\hline 0,01 & 0,01 & 0,01 & 0,01 & 0,01 & 0,01 & 0,01 & 0,01 & 0,01 & 0,01 & 0,01 & 0,02 & 0,02 & 0,01 & 0,01 & 0,01 & 0,01 & 0,01 & 0,01 & 0,01 & 0,01 & 0,01 & 0,01 & 0,01 \\
\hline 0,01 & 0,01 & 0,01 & 0,01 & 0,01 & 0,01 & 0,01 & 0,01 & 0,01 & 0,01 & 0,01 & 0,01 & 0,01 & 0,01 & 0,01 & 0,02 & 0,01 & 0,01 & 0,01 & 0,02 & 0,02 & 0,02 & 0,01 & 0,02 \\
\hline 0,00 & 0,00 & 0,00 & 0,01 & 0,01 & 0,01 & 0,01 & 0,01 & 0,01 & 0,01 & 0,00 & 0,01 & 0,01 & 0,01 & 0,01 & 0,01 & 0,01 & 0,01 & 0,01 & 0,01 & 0,01 & 0,01 & 0,01 & 0,01 \\
\hline 0,01 & 0,00 & 0,01 & 0,00 & 0,00 & 0,01 & 0,01 & 0,01 & 0,00 & 0,00 & 0,00 & 0,01 & 0,01 & 0,00 & 02 & 0,01 & 0,01 & 0,01 & 0,01 & 0,01 & 01 & 0,01 & ,01 & 0,01 \\
\hline 0,04 & 0,04 & 0,05 & 0,05 & 0,05 & 0,06 & & 0,05 & 0,04 & 0,05 & 0,05 & 0,07 & 0,08 & 0,04 & 0,07 & 0,06 & 0,08 & 0,07 & 0,07 & 0,09 & 09 & 0,09 & 0,07 & 0,10 \\
\hline 0,03 & 0,02 & 0,05 & 0,03 & 0,04 & 0,03 & 0,03 & 0,04 & 0,03 & 0,05 & 0,04 & 0,03 & 0,02 & 0,03 & 0,03 & 0,03 & 0,05 & 0,06 & 0,02 & 0,05 & 0,03 & 0,03 & 0,02 & 0,03 \\
\hline 0,00 & 0,00 & 0,02 & 0,00 & 0,00 & 0,00 & 0,00 & 0,00 & 0,00 & 0,00 & 0,00 & 0,00 & 0,00 & 0,00 & 0,02 & 0,00 & 0 & 0,01 & 0 , & 0,00 & 00 & 0,00 & 00 & 0,00 \\
\hline 0,02 & 0,02 & 0,02 & 0,02 & 0,02 & 0,02 & 0,02 & 0,03 & 0,02 & 0,02 & 0,02 & 0,02 & 0,01 & 0,05 & 0,02 & 0,02 & 0,02 & 0,02 & 0,02 & 0,02 & 0,02 & 0,02 & 0,02 & 0,02 \\
\hline 0,09 & 0,05 & 0,07 & 0,06 & 0,06 & 0,07 & 0,06 & 0,07 & 0,06 & 0,05 & 0,06 & 0,05 & 0,05 & 0,11 & 0,15 & 0,05 & 0,06 & 0,05 & 0,05 & 0,07 & 0,06 & 0,06 & 0,05 & 0,06 \\
\hline 0,04 & 0,02 & 0,05 & 0,07 & 0,06 & 0,08 & 0,06 & 0,07 & 0,07 & 0,05 & 0,03 & 0,03 & 0,03 & 0,02 & 0,03 & 0,03 & 0,03 & 0,04 & 0,03 & 0,04 & 0,04 & 0,04 & 0,03 & 0,04 \\
\hline 0,01 & 0,00 & 0,01 & 0,01 & 0,01 & 0,01 & 0,01 & 0,01 & 0,01 & 0,01 & 0,01 & 0,01 & 0,01 & 0,01 & 0,01 & 0,01 & 0,01 & 0,01 & 0,01 & 0,01 & 0,01 & 0,01 & 0,01 & 0,01 \\
\hline 0,01 & 0,01 & 0,03 & 0,01 & 0,01 & 0,01 & 0,02 & 0,01 & 0,01 & 0,0 & 0,01 & 0,0 & 0,01 & 0,0 & 0,02 & $0, \mathrm{C}$ & 0,0 & 0,01 & 0,0 & 0,01 & 0,01 & 0,01 & 01 & 0,01 \\
\hline 1,19 & 0,14 & 0,01 & 0,01 & 0,01 & 0,01 & 0,00 & 0,01 & 0,02 & 0,01 & 0,01 & 0,01 & 0,00 & 0,00 & 0,01 & 0,00 & 0,01 & 0,01 & 0,01 & 0,01 & 0,01 & 0,01 & 0,01 & 0,01 \\
\hline 0,00 & 1,00 & 0,00 & 0,00 & 0,00 & 0,00 & 0,00 & 0,00 & 0,00 & 0,00 & 0,00 & 0,00 & 0,00 & 0,00 & 0,00 & 0,00 & 0,00 & 0,00 & 0,00 & 0,00 & 0,00 & 0,00 & 0,00 & 0,00 \\
\hline 0,00 & 0,00 & 04 & 00 & ,00 & 0,00 & 0,00 & 0,00 & 0,00 & 0,0 & 0,00 & 0,0 & 0,00 & 0,0 & 0,0 & 0,0 & 0,00 & 0,0 & 0,0 & $0, \mathrm{C}$ & 0,00 & 0,00 & 0,00 & 0,00 \\
\hline 0,00 & 0,00 & 0,00 & 1,17 & 0,01 & 0,01 & 0,01 & 0,00 & 0,00 & 0,00 & 0,00 & 0,01 & 0,01 & 0,00 & 0,01 & 0,01 & 0,01 & 0,01 & 0,01 & 0,01 & 0,01 & 0,01 & 0,01 & 0,01 \\
\hline 0,04 & 0,04 & 0,04 & 05 & 1,08 & 0,06 & 0,06 & 0,0 & 0,07 & 0,1 & 0,04 & 0,07 & 0,06 & 0,0 & 0,07 & 0,06 & 0,08 & 0,08 & 0,07 & 0,09 & 0,10 & 0,10 & 0,08 & 0,10 \\
\hline 0,04 & 0,04 & 0,10 & 0,05 & 0,05 & 1,14 & 0,05 & 0,05 & 0,05 & 0,05 & 0,04 & 0,07 & 0,06 & 0,04 & 0,07 & 0,06 & 0,08 & 0,08 & 0,07 & 0,09 & 0,10 & 0,10 & 0,07 & 0,10 \\
\hline 0,02 & 0,01 & 0,02 & 0,02 & 0,02 & 0,02 & 1,19 & 0,02 & 0,02 & 0,02 & 0,01 & 0,03 & 0,02 & 0,02 & 0,03 & 0,02 & 0,03 & 0,03 & 0,03 & 0,04 & 0,04 & 0,04 & 0,03 & 0,04 \\
\hline 0,00 & 0,00 & 0,00 & 0,01 & 0,01 & 0,01 & & & 0,00 & 0,0 & & & & 0 , & & 0 , & & 0 , & & 0 , & & 01 & & 0,01 \\
\hline 0,03 & 0,02 & 0,03 & 0,04 & 0,05 & 0,05 & 0,05 & 0,04 & 1,36 & 0,14 & 0,02 & 0,04 & 0,03 & 0,03 & 0,04 & 0,04 & 0,05 & 0,05 & 0,04 & 0,05 & 0,06 & 0,06 & 0,04 & 0,06 \\
\hline 0,05 & 0,04 & 0,05 & 0,08 & 0,08 & 0,09 & 0,08 & 0,0 & 0,07 & 1 , & 0,05 & 0,0 & 0,06 & 0,0 & 0,09 & 0,07 & 0,09 & 0,13 & 0,08 & 0,10 & 0,11 & 0,11 & 0,08 & 0,11 \\
\hline 0,00 & 0,00 & 0,00 & 0,01 & 0,00 & 0,01 & 0,01 & 0,01 & 0,00 & 0,00 & 1,01 & 0,01 & 0,01 & 0,00 & 0,01 & 0,01 & 0,02 & 0,01 & 0,01 & 0,01 & 0,01 & 0,01 & 0,01 & 0,01 \\
\hline 0,07 & 0,05 & 0,06 & 0,06 & 0,07 & 0,07 & 0,07 & 0,09 & 0,06 & 0,07 & 0,05 & 1,45 & 0,06 & 0,06 & 0,08 & 0,07 & 0,10 & 0,09 & 0,07 & 0,11 & 0,10 & 0,09 & 0,07 & 0,10 \\
\hline 0,01 & 0,01 & & 0,01 & & 0,01 & 0,01 & 0,02 & & 0,01 & 0,01 & 0,02 & 1,05 & 0,01 & 0,02 & 0,02 & & 0,02 & 0,05 & 0,02 & 0,02 & 0,02 & 0,01 & 0,02 \\
\hline 0,48 & 0,32 & 0,45 & 0,27 & 0,27 & 0,37 & 0,30 & 0,39 & 0,30 & 0,26 & 0,31 & 0,15 & 0,16 & 1,31 & 0,24 & 0,13 & 0,18 & 0,18 & 0,14 & 0,25 & 0,18 & 0,18 & 0,14 & 0,19 \\
\hline 0,08 & 0,06 & 0,08 & 0,0 & & & & 0,09 & 0,09 & 0,07 & 0,06 & 0,08 & 0,07 & 0,10 & 1,26 & 0,09 & 0,14 & 0,09 & 0,08 & & 0,10 & 0,10 & 0,08 & 0,11 \\
\hline 0,03 & 0,03 & 0,03 & 0,03 & 0,03 & 0,04 & 0,03 & 0,04 & 0,03 & 0,03 & 0,03 & 0,04 & 0,03 & 0,04 & 0,06 & 1,04 & 0,09 & 0,05 & 0,03 & 0,05 & 0,05 & 0,04 & 0,03 & 0,05 \\
\hline 0,04 & 0,03 & 0,04 & 0,04 & 0,04 & 0,05 & 0,04 & 0,05 & 0,05 & 0,04 & 0,04 & 0,06 & 0,04 & 0,04 & 0,07 & 0,05 & 1,24 & 0,05 & 0,04 & 0,06 & 0,05 & 0,05 & 0,04 & 0,06 \\
\hline 0,06 & 0,05 & 0,05 & 0,06 & 0,07 & 0,07 & 0,07 & 0,07 & 0,06 & 0,06 & 0,06 & 0,08 & 0,07 & 0,06 & 0,09 & 0,08 & 0,15 & 1,10 & 0,08 & 0,12 & 0,11 & 0,11 & 0,08 & 0,11 \\
\hline 0,14 & 0,13 & 0,14 & 0,17 & 0,17 & 0,18 & 0,17 & 0,16 & 0,15 & 0,15 & 0,13 & 0,22 & 0,18 & 0,17 & 0,23 & 0,21 & 0,30 & 0,24 & 1,23 & 0,28 & 0,31 & 0,30 & 0,23 & 0,32 \\
\hline 0,01 & 0,01 & 0,01 & 0,01 & 0,01 & 0,01 & 0,01 & 0,01 & 0,01 & 0,01 & 0,01 & 0,01 & 0,01 & 0,01 & 0,01 & 0,01 & 0,01 & 0,01 & 0,01 & 1,01 & 0,01 & 0,01 & 0,01 & 0,01 \\
\hline 0,01 & 0,01 & 0,01 & 0,01 & 0,01 & 0,01 & 0,01 & 0,01 & 0,01 & 0,01 & 0,01 & 0,01 & 0,01 & 0,01 & 0,01 & 0,01 & 0,01 & 0,01 & 0,01 & 0,02 & 1,02 & 0,02 & 0,01 & 0,02 \\
\hline 0,26 & 0,26 & 0,32 & 0,27 & 0,28 & 0,29 & 0,28 & 0,30 & 0,23 & 0,27 & 0,26 & 0,51 & 0,25 & 0,30 & 0,57 & 0,34 & 0,64 & 0,57 & 0,20 & 1,06 & 1,17 & 1,24 & 0,18 & 0,25 \\
\hline 0,66 & 0,56 & 0,56 & 0,89 & 0,91 & 0,90 & 0,92 & 0,79 & 0,78 & 0,74 & 0,59 & 0,97 & 1,06 & 0,66 & 0,96 & 1,11 & 1,12 & 1,02 & 1,54 & 0,76 & 0,77 & 0,74 & 1,57 & 0,78 \\
\hline 0,73 & 0,66 & 0,71 & 0,91 & 0,93 & 0,94 & 0,94 & 0,87 & 0,79 & 0,80 & 0,68 & 1,20 & 1,01 & 0,77 & 1,25 & 1,14 & 1,43 & 1,30 & 1,33 & 1,57 & 1,68 & 1,72 & 1,34 & 1,81 \\
\hline
\end{tabular}

Fonte: Matriz de Contabilidade Social do Paraná - 1998

Nota: Cálculo realizado pelos autores

RER, Rio de Janeiro, vol. 44, no 04, p. 731-750, out/dez 2006 - Impressa em dezembro 2006 


\section{Anexo 2}

\section{Códigos das atividades da matriz de contabilidade social do Paraná}

Quadro A.2 - Códigos das atividades da matriz de contabilidade social do Paraná

\begin{tabular}{|r|l|}
\hline CÓDIGO & ATIVIDADES \\
\hline 1 & Agropecuária \\
2 & Extrativa Mineral \\
3 & Extração de petróleo e Gás \\
4 & Minerais não - metálicos \\
5 & Siderurgia \\
6 & Metalurgia Não-ferrosos \\
7 & Outros Metalúrgicos \\
8 & Máquina e Tratores \\
9 & Material Elétrico \\
10 & Equipamentos Eletrônicos \\
11 & Automóveis, Caminhões e Ônibus \\
12 & Outros veículos e Peças \\
13 & Madeira e mobiliário \\
14 & Papel e Gráfica \\
15 & Indústria da Borracha \\
16 & Química ñ petro.e Ref. Do Petróleo \\
17 & Ref. de Petro.e indústria Petroq. \\
18 & Químicos Diversos \\
19 & Farmacêutica e Perfumaria \\
20 & Artigos de Plástico \\
21 & Indústria Têxtil \\
22 & Artigos do Vestuário \\
23 & Fabricação de Calçados \\
24 & Indústria do Café \\
25 & Benef. de Prod. Origem Vegetal \\
26 & Abate de Animais \\
27 & Indústria de Laticínios \\
28 & Indústria de Açúcar \\
29 & Fabricação de Óleos vegetais \\
30 & Outros Produtos Alimentares \\
31 & Indústrias Diversas \\
32 & Serviços Indust. Utilid. Pública \\
33 & Construção Civil \\
& \\
\hline
\end{tabular}


Determinação dos multiplicadores da matriz de contabilidade social, da indústria de base florestal paranaense - 1998

\begin{tabular}{|l|l|l|}
34 & Comércio \\
35 & Transportes \\
36 & Comunicações \\
37 & Instituições Financeiras \\
38 & Serviços \\
39 & Aluguel de Imóveis \\
40 & Administração Pública \\
41 & Serv. Priv. não-mercantis \\
\hline 42 & Trabalho \\
43 & Capital \\
\hline 44 & Famílias \\
\hline
\end{tabular}

Recebido em março de 2004 e revisto em abril de 2006. 